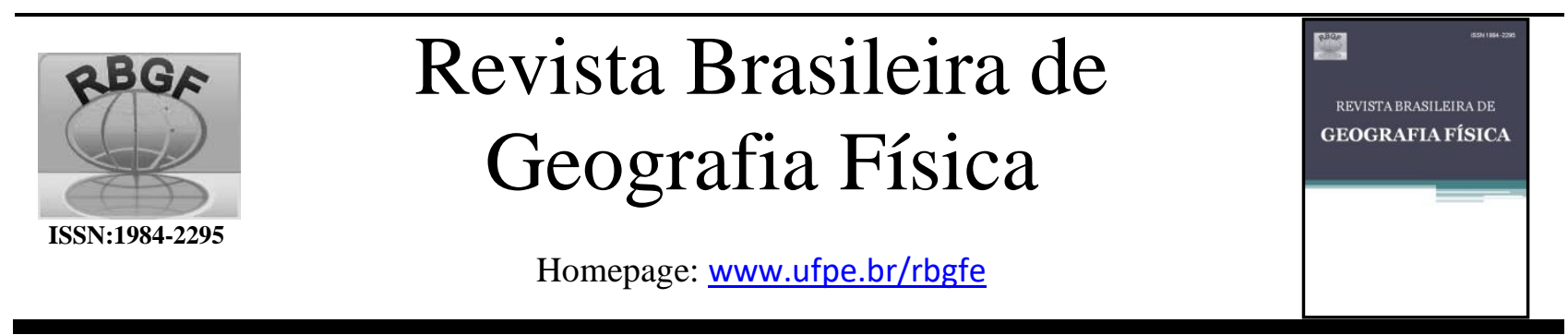

\title{
Análise de Componente do Regime Hidrológico da Bacia do Rio Amazonas em Anos de Eventos Climáticos
}

\author{
Rogério de Souza Aguiar ${ }^{1}$, Edson José Paulino da Rocha², \\ José Augusto de Souza Júnior ${ }^{3}$, Joyse Tatiane Souza dos Santos ${ }^{4}$, Josiane Sarmento dos Santos 5 .
}

1 - Professor Universitário - Escola Superior da Amazônia - eng.rogerio.aguiar1 @ gmail.com (autor correspondente).2 - Professor Visitante - Programa de Pós Graduação em Ciências Ambientais - UFPA.3 - Pesquisador de Pós Doutorado - Programa de Pós Graduação em Ciências Ambientais - UFPA.4 - Doutoranda - Programa de Pós Graduação em Ciências Ambientais - UFPA.5 - Doutoranda - Programa de Pós Graduação em Ciências Ambientais - UFPA.

Artigo submetido em 11/07/2018 e aceite em 19/03/2019

\begin{abstract}
R E S U M O
As cheias e vazantes do rio Amazonas passaram a ser mais persistentes ao longo dos anos. Este estudo busca analisara influência da variabilidade temporal em escala de bacia hidrográfica sobre o regime do rio Amazonas, a partir das vazões da estação hidrológica da Agência Nacional de Águas - ANA, localizada em Óbidos, no Estado do Pará em uma série histórica de janeiro/1970 a dezembro/2013. Além do tempo, o estudo analisou a intensidade do El Niño e La Niña. Como esperado, o tempo influenciou na vazão média interanual encontrada de $98.723 \mathrm{~m}^{3} / \mathrm{s}$ para os 44 anos da série analisada. Porém com variabilidade anual do regime do rio Amazonas de intensos fluxos, com avazão variando de ordem de 72.380 $\mathrm{m}^{3} / \mathrm{s}$ (como em 1997) no regime de vazante até uma ordem de $131.620 \mathrm{~m}^{3} / \mathrm{s}$ (como em 1974) no regime de cheia. Também foi identificado que fenômenos de El Niño e La Niña modularam eventos climáticos extremos sobre as vazões da Bacia Amazônica em cada ano. A análise interanual mostrou que os anos de baixas vazões, possuíam a característica de persistência de ocorrência em relação às altas vazões. A partir de 1989, houve um aumento em relação à amplitude médiada vazão de $87.727 \mathrm{~m}^{3} / \mathrm{s}$ devido a fortes níveis mínimos registrados.Ao analisar a vazão normalizada percebeu-se que na maioria dos anos de baixa vazão foramtambém anos do fenômeno El Niño.Constatado esta persistência de baixas vazões, investigaram-se os fatores de armazenamento e disponibilidade do rio Amazonas.

Palavras-chave:Vazões temporais. Manutenção Ecológica. Rio Amazonas.
\end{abstract}

\section{Analysis of Hydrological Regime Componentof the Amazonas River Basin in Years of Climate Events.}

\begin{abstract}
The floods and drains of the Amazon River have become more persistent over the years. This study seeks to analyze the influence of the temporal variability in the basin scale on the Amazon river regime, from the flows of the hydrological station of the National Water Agency - ANA, located in Óbidos, State of Pará, in a historical series from January/1970 to December /2013. Besides time, the study analyzed the intensity of El Niño and La Niña. As expected, time influenced the annual interannual flow rate of $98,723 \mathrm{~m}^{3} / \mathrm{s}$ for the 44 years of the analyzed series. However, with an annual variability of the Amazon river regime of intense flows, with an increase of 72,380 $\mathrm{m}^{3} / \mathrm{s}$ (as in 1997) in the effluent regime up to an order of 131,620 $\mathrm{m}^{3} / \mathrm{s}$ (as in 1974) in the flood regime. It was also identified that El Niño and La Niña phenomena modulated extreme climatic events on the Amazon Basin flows each year. The year-on-year analysis showed that the years of low flows had a persistence of occurrence in relation to high flows. As of 1989, there was an increase in relation to the average flow amplitude of $87,727 \mathrm{~m}^{3} / \mathrm{s}$ due to the strong minimum levels recorded. Analyzing the normalized flow rate, it was observed that in most of the years of low flow there were also years of the El Niño phenomenon. Considering this persistence of low flows, we investigated the storage and availability factors of the Amazon River.

Keywords: Time flows. Ecological Maintenance.Amazonriver.
\end{abstract}

\section{Introdução}

Nos corpos hídricos há uma relação de causa e efeito dos processos ocorrentes na bacia hidrográfica (Mendes e Cirilo, 2013), como os processos hidrológicos, envolvendo vários fenômenos associados à circulação natural da água (Loewen e Pinheiro, 2017).

Em estudos hidrológicos há a necessidade de se entender os processos hidrológicos em bacias hidrográficas que controlam o movimento da água 
(Viana et al. 2018), pois segundo Santos et al. (2013) permitem auxiliar na preservação dos recursos hídricos e, consequentemente, no desenvolvimento das regiões.

O movimento da água nos processos hidrológicos ocorre de forma diferenciada. E nas bacias hidrográficas em diferentes escalas (Arnoldet al., 2012). Sendo que amais simples de formular modelo é a escala temporal, como número de parâmetros menor do que em modeloshidrológicos em base diária (Lucaset al., 2009).

Nesse sentido, em estudos hidrológicos torna-se importante estimar adequadamente os fluxos extremos altos esperados de um rio para a avaliação e projeto de risco de inundação, operação e gerenciamento de estruturas hidráulicas (Prosdocimi et al., 2014). As inundações excessivas resultantes de altos fluxos tiveram importantes conseqüências socioeconômicas em todo o mundo. Durante o período de 2001 a 2014, mais de um bilhão de as pessoas do mundo foram afetadas por inundações, e quase 80 mil morreram (EM-DAT / OFDA / CRED, 2015).

No Amazonas ocorrem as inundações graduais, em espaço-tempo diferente, sendo que no primeiro trimestre do ano, a cota de inundação ocorre nos municípios das calhas dos rios Juruá, Purus e Madeira, enquanto que no segundo trimestre, ocorre nos municípios das calhas do Solimões, Amazonas e Negro. As vazantes ou estiagens ocorrem no segundo semestre do ano no estado do Amazonas (BRASIL, 2013).

Além disso, segundo Almeida (2014), em estudos hidrológicos é importante considerar que os eventos extremos de natureza climática, embora sejam processos essencialmente naturais (ou pelo menos parcialmente naturais), têm consequências bastante diversas, de acordo com a vulnerabilidade das populações instaladas nestes ambientes, e não atingem a todos os moradores com a mesma intensidade.

Em hidrologia, séries temporais são fontes valiosas de informações que podem ser consultadas para a caracterização de variáveis nas mais diversas áreas do conhecimento. Tais séries são de fundamental importância para o entendimento do ciclo hidrológico, sendo empregadas na gestão de sistemas hídricos. O uso de séries temporais hidrológicas é tradicionalmente considerado em modelos estocásticos que objetivam reproduzir o comportamento de determinado fenômeno. Citamse como exemplos modelos de geração de séries sintéticas de chuvas (Detzel e Mine, 2011; Rasmussen, 2013) e vazões (Detzel et al., 2014;
Niu e Sivakumar, 2013). Alternativamente, séries hidrológicas são aplicadas no dimensionamento de reservatórios (Silva e Portela, 2013), análises relacionadas à demanda de água (Adamowski et al., 2012), avaliação da disponibilidade hídrica de rios (Cruz e Tucci, 2008), entre muitos outros usos.

Na Amazônia, Guedes (2013) cita que não apenas a escala temporal do estoque de água é importante, mas também em que área essa flutuação acontece mais rapidamente, pois pode indicar áreas mais potencialmente vulneráveis a estiagens prolongadas ou mesmo que sofreram impactos mais rápidos das cheias.

Sendo assim, além da preocupação com os altos fluxos do rio em determinadas áreas na Amazônia tem-se os eventos extremos, os fenômenos meteorológicos, como o El Niño, que influenciam no regime hidrológico de cheia e vazante.

O trabalho buscou estudar a principal componente da distribuição de água na bacia Amazônica e conhecer sua disposição de frequência de ocorrência.

\section{Material e métodos}

Dados de vazão

Esse trabalho abrangeu a área da bacia do rio Amazonas em Óbidos, utilizando dados de vazão da Agência Nacional de Águas (ANA) entre os anos de 1970 a 2013. A metodologia utilizada será descrita detalhadamente nas sessões seguintes.

A Região Amazônica possui uma grande extensão, entretanto as estações de medidas de vazão próximas a sua foz são escassas, e por isso optou-se pela estação fluviométrica de Óbidos (17050001), por ser a estação mais próxima da foz com uma série temporal de dados bastante longa e com pouca falha, facilitando a determinação do comportamento hidrológico da bacia do rio Amazonas.

Assim, a estação fluviométrica para medida de descargas do rio Amazonas, mais a jusante, é a de Óbidos no estado do Pará (Figura 1). Nessa estação, a influência da maré do Oceano Atlântico pode ser considerada como negligenciável no momento (trabalhos de pesquisas em curso).

Portanto, a análise do regime hidrológico e da disponibilidade hídrica da bacia do rio Amazonas foi feita utilizando dados mensais de vazão fluvial ( $\left(\mathrm{em} \mathrm{m}^{3} / \mathrm{s}\right)$ da estação fluviométrica de Óbidos da ANA no período de 1970 a 2013, totalizando 44 anos de dados. Haja vista que, segundo Sampaio (2012), do ponto de vista hidrológico, Óbidos controla $80 \%$ do total da vazão do Amazonas na foz, através de sua estação 
hidrológica instalada no início do século XX e a superfície da bacia hidrográfica é de $4.680 .000 \mathrm{~km}^{2}$ (superfície global da bacia: $6.100 .000 \mathrm{~km}^{2}$ ). Portanto, essa estação mede as maiores descargas do mundo (Callède, 1996).

No processo de análise e consistência de dados de vazão, o tratamento das falhas foi efetuado o preenchimento através de procedimento estatístico (inserindo linha de tendência à relação dispersa dos dados amostrais da variável vazão), adotando-se o maior coeficiente de correlação $\mathrm{R}^{2}$, como modelo explicativo que melhor indica correlação linear positiva.

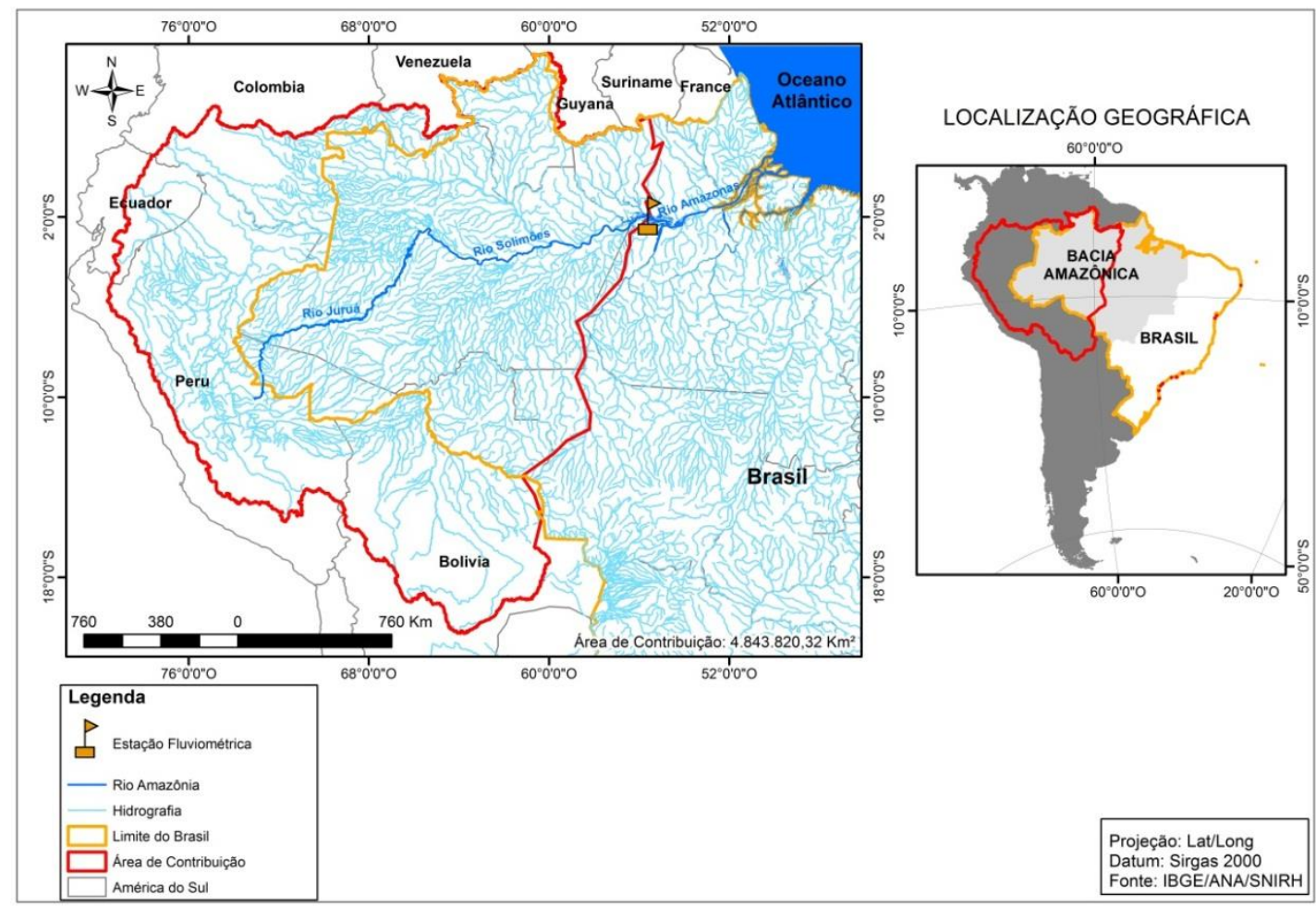

Figura 1 - Área de contribuição da estação fluviométrica de Óbidos detalhando a seção de medições de descarga. (Fonte: Do autor).

Outro material utilizado nesse estudo foi o histórico de eventos climáticos extremos, El Niño e La Niña, que afetaram a Bacia Amazônica
Brasileira, no período de 1970 a 2013 , conforme mostrado na Tabela 1.

\begin{tabular}{llllll}
\hline EL NIÑO & & & LA NIÑA & & \\
\hline FRACO & MODERADO & FORTE & FRACO & MODERADO & FORTE \\
$1976-1977$ & $1968-1970$ & $1972-1973$ & $1983-1984$ & $1970-1971$ & $1973-1976$ \\
$1977-1978$ & $1986-1988$ & $1982-1983$ & $1984-1985$ & $1998-1999$ & $1988-1989$ \\
$1979-1980$ & $1991-1992$ & $1997-1998$ & $1995-1996$ & $2007-2008$ & $1999-2000$ \\
$2004-2005$ & $1994-1995$ & & $2000-2001$ & & $2010-2011$ \\
$2006-2007$ & $2002-2003$ & & $2005-2006$ & & \\
& $2009-2010$ & & $2008-2009$ & & \\
& & & $2011-2012$ & & \\
\hline
\end{tabular}

Tabela 1 - Períodos de ocorrência dos fenômenos de El Niño e La Niñano período de 1970-2013. FONTE: Adaptado de CPTEC/INPE (2017).

Método

Os métodos utilizados podem ser apresentados nas seguintes etapas:

Etapa 1:Analise do regime hidrológico do rio Amazonas e a variabilidade anual e interanual da vazão.
A análise do regime hidrológico anual ocorreu através da média (equação 1) dos totais anuais e mensais de vazões observadas na estação hidrológica de Óbidos no período de janeiro/1970 a dezembro/2013. 
$\bar{x}=\frac{1}{N} \sum_{i=1}^{N}\left(x_{i}\right)$

Onde,

$N$ - número de dados utilizados.

O regime hidrológico normal anual do rio Amazonas foi analisado através de uma faixa de desvio padrão amostral (equação 2) positivo e negativo a partir da média das vazões observadas. Além disso, os picos dos dados de vazão dentro da série histórica ocorreram pelos valores de máximos e mínimos absolutos de vazões ao longo deste tempo especificado.

$\sigma=\sqrt[2]{\frac{1}{N} \sum_{i=1}^{N} \frac{\left(x_{i}-\bar{x}\right)^{2}}{(N-1)}} \quad(2) .:{ }^{\delta}{ }_{\text {MÊS } 1}=\mid \mathrm{Q}_{\text {MédMês1 }} \quad-$
Q $_{\text {MédMês } 1 / / \mathrm{N}}$

Onde,

$\overline{\boldsymbol{x}}$ - média aritmética dos dados;

$N$ - número de dados utilizados;

$\boldsymbol{x}_{\boldsymbol{i}}$ - dados observados no tempo, de 1 a N.

$\sigma$ - desvio padrão.

A análise do regime hidrológico interanual ocorreu através de uma faixa de desvio padrão amostral (equação 2) positivo e negativo à partir da média anual das vazões mínimas observadas de 1970 a 2013.

Além disso, foi analisada individualmente, a amplitude ocorrida entre a mínima e a máxima vazão ocorrida em cada um dos 44 anos.

A análise da variação do regime hidrológico diante aos eventos de cheias e vazantes extremas ocorreu através da aplicação da equação 3 das vazões anuais ajustadas, para identificar os valores de vazão no período de vazante e de cheia, variando de -1 a 1 , onde os valores negativos e o zero referem-se aos eventos de vazante e os valores positivos aos eventos de cheia.

$Q n=Q i-\bar{x}$

Onde,

$\boldsymbol{Q}_{\boldsymbol{n}}$ - vazão normalizada;

$\boldsymbol{Q}_{\boldsymbol{i}}$ - vazão anual observada;

$\overline{\boldsymbol{x}}$ - média aritmética das vazões observadas.

Devido os eventos climáticos extremos passar a ser mais frequentes na Amazônia, desde a estiagem prolongada de 2005, para este trabalho, buscou-se estudar a variabilidade de vazão dos corpos hídricos nesta região somente a partir dos fenômenos de El Niño ou La Niña ao longo da série histórica, identificados e analisados por meio da
Tabela 01 de ocorrências dos fenômenos de El Niño e La Niña, que ilustra suas intensidades, disponibilizada no portal do CPTEC (http://enos.cptec.inpe.br/).

Etapa 2: Determinar a disponibilidade hídrica do rio Amazonas.

a) Método dos Percentis (especificamente a ordem quantílica Q95\%)

A partir da vazão pelo método dos Percentis (ordem quantílica Q95\%) adotada pela ANA para regiões hidrográficas do Brasil em rios sem regularização, este trabalho buscou estudar a disponibilidade hídrica do rio Amazonas.

A disponibilidade hídrica do rio Amazonas foi determinada a partir da comparação da vazão utilizada pela ANA, a Q95\%, tanto para as séries históricas de vazões dos anos (análise interanual) quanto para as séries históricas de vazões mensais dos anos da série (análise anual).

Para determinação do regime de vazões disponíveis neste estudo foi utilizada a análise dos valores de vazão mínima por representar os períodos mais críticos e por possibilitar uma sazonalidade similar ao regime hidrológico natural de um rio.

Sendo utilizada para a estação fluviométrica analisada, a metodologia de Tucci que consiste em estabelecer " $n$ " intervalos de classe de acordo com a magnitude. $\mathrm{O}$ gráfico permite visualizar rapidamente a disponibilidade hídrica de um curso d'água e assim obter as frequências " $f$ " em que ocorrem determinadas vazões, a partir da contagem do número de vazões em cada intervalo, conforme sequência a seguir:

I. Ordenamento dos valores mensais de vazão (de 1970 a 2013) em ordem crescente;

II. A cada valor ordenado associou-se um valor " $m$ " a posição de plotagem, que equivale a ordem de excedência;

III. Em paralelo foi definido um valor que representa a porcentagem de um determinado valor de vazão, dado por $m /(n+1)$, sendo " $n$ " o total dos dados de vazão utilizados;

IV. Com os dados organizados na forma de uma curva de permanência calculou-se a média aritmética da série e o $\mathrm{Q}_{95 \%}$ (adotado como referência a partir da utilização, em boa parte das concessões de outorgas, pela Agência Nacional de Águas).

b) Análise da disponibilidade hídrica e da vazão Q95\% 
Como o objetivo é estudar o rio Amazonas em períodos críticos de oferta d'água, a análise da disponibilidade hídrica foi possível a partir da inserção da curva das vazões Q95\% mensais sobre os dados de vazões mínimas absolutas para cada ano da série observada.

Para identificar os anos em que o rio Amazonas apresentou períodos de menor oferta hídrica, onde são considerados períodos críticos, as descargas muito abaixo da vazão recomendada em lei para esta série temporal a ser mantida em seu leito para o bom funcionamento do ecossistema aquático amazônico.

Para determinação da disponibilidade hídrica $\left(\mathrm{DH}_{\mathrm{ti}}\right)$ do rio Amazonas para cada mês ou no ano, utiliza-se a equação:

$D H_{t i}=Q_{t i}-Q_{95 \%}(4)$

Onde,

$\boldsymbol{Q}_{t i}$ observações de cada mês ou a observação anual

A disponibilidade hídrica por um determinado período de tempo deve ser entendida como a diferença entre vazão observada, que para este trabalho será aquela disponível no mês e a vazão de referência $\mathrm{Q} 95 \%$, como mostrado na equação.

Este trabalho estudou a vazão mínima tanto para os anos de 1970 a 2013, como também as vazões mínimas para os meses de janeiro até dezembro de cada ano desta série, devido às flutuações do rio Amazonas entre os meses de cada ano da série.

Assim, buscou-se regularizar as vazões mínimas mensais a partir da vazão utilizada pela ANA, a Q95\%, e desta forma regularizar as vazões mínimas remanescentes em cada mês de um possível ano com déficit de água.

A análise da disponibilidade hídrica mensal ocorreu através da aplicação da equação 3 pela diferença da vazão observada do regime hidrológico diante a vazão Q95\% de cada mês, para identificar os anos de menor oferta de água, onde os anos com valores positivos referem-se as vazões mínimas de cada ano deste rio a serem superadas em 95\% do tempo da série histórica, os valores negativos ou igualadas (zero) referem-se a vazão mínima observada com risco de não acontecer em $5 \%$ do tempo naquele ano, onde a descarga do rio fica abaixo do valor mínimo necessário para a manutenção do meio biótico e recomendado em lei.

Se a disponibilidade hídrica for positiva, isso significa que pode haver aproveitamento adequado de seus recursos hídricos. Todavia, caso a disponibilidade hídrica seja negativa, o aproveitamento pode ser comprometido nesse período.

A análise da oferta hídrica interanual ocorreu através da inserção da curva de Q95\% de cada ano da série sobre as vazões mínimas observadas, para identificar os anos de menor oferta de água, onde os anos com valores positivos referem-se as vazões mínimas de cada ano deste rio a serem superadas em 95\% do tempo da série histórica, os valores negativos ou igualadas (zero) referem-se a vazão mínima observada com risco de não acontecer em 5\% do tempo naquele ano, onde a descarga do rio fica abaixo do valor mínimo necessário para a manutenção do meio biótico e recomendado em lei.

Logo em seguida levará em consideração a influência de um evento extremo sobre a diminuição da vazão através do valor da Q95\%.

\section{Resultados e discussão}

Comportamento da componente vazão do rio amazonas no tempo

\section{Regime hidrológico anual}

A Figura 2 apresentou um período de cheia nos meses de abril a julho. Sendo que foi no mês de junho que a vazão alcançou pico máximo entorno de $239.000 \mathrm{~m} 3 / \mathrm{s}$ conforme observado, também, na Tabela 2.

Enquanto que os meses de setembro a dezembro apresentaram característica de vazante, com a vazão média alcançando valor mínimo de $105.000 \mathrm{~m}^{3} / \mathrm{s}$ em novembro. Tal expressiva variabilidade de amplitude entre picos de máximo e mínimo, entorno de $134.000 \mathrm{~m}^{3} / \mathrm{s}$, é a característica do comportamento da vazão média do rio Amazonas que compõe a sazonalidade do regime hidrológico no período analisado. Callède et al. (2002) encontrou, na amplitude mínima da vazão afluente dos tributários da parte sul e o pico de descarga em Óbidos, a vazão média anual de $163.000 \mathrm{~m}^{3} / \mathrm{s}$. Ao analisar esta variabilidade pode-se notar a existência de uma diminuição da amplitude do rio Amazonas neste trabalho em escala sazonal.

Observa-se ainda na Figura 2 que no mês de setembro há um comportamento de transição decrescente, não característico, entre vazão sazonal máxima e vazão sazonal mínima, com início no mês de julho. Guedes (2013) identificou semelhante sazonalidade no ciclo hidrológico em Óbidos ao longo de 104 anos (1903-2007). Em seu estudo observou que as cheias ocorrem nos meses de maio e junho com de $97 \%$ de chance de ocorrer 
nesse período, e as vazantes com $86 \%$ de chance de ocorrerem entre outubro e novembro.

Além disso, os picos de máximas e de mínimas vazões, mostrados na Figura 02, assemelham-se a estudos de 31 anos (1982-2012) de Coutinho (2016), onde na estação de Óbidos aparecem as maiores vazões da bacia Amazônica.
O resultado desse autor mostrou uma vazão de $95.000 \mathrm{~m}^{3} / \mathrm{s}$ para o período de mínimo. Logo, subestimando o encontrado neste estudo, de $105.000 \mathrm{~m}^{3} / \mathrm{s}$. Entretanto, a vazão apresentada, pelo mesmo autor, de $260.000 \mathrm{~m}^{3} / \mathrm{s}$ para o período de máximo, superestimou a vazão encontrada neste trabalho, de apenas $239.000 \mathrm{~m}^{3} / \mathrm{s}$.

\begin{tabular}{|c|c|c|c|c|c|c|c|}
\hline Cód & $\begin{array}{c}\text { Área de superfície } \\
\left(\mathrm{Km}^{2}\right)\end{array}$ & Jan & Fev & Mar & Abr & Mai & Jun \\
\hline \multirow{3}{*}{17050001} & \multirow{2}{*}{4.680 .000} & 139922 & 164258 & 191390 & 219631 & 237199 & 239104 \\
\cline { 3 - 8 } & & Jul & Ago & Set & Out & Nov & Dez \\
\cline { 3 - 8 } & & 223552 & 192542 & 150612 & 114164 & 105187 & 117541 \\
\hline
\end{tabular}

Tabela 2 - Vazões médias do rio Amazonas ( $\left.\mathrm{m}^{3} / \mathrm{s}\right)$. (Fonte: Do autor).

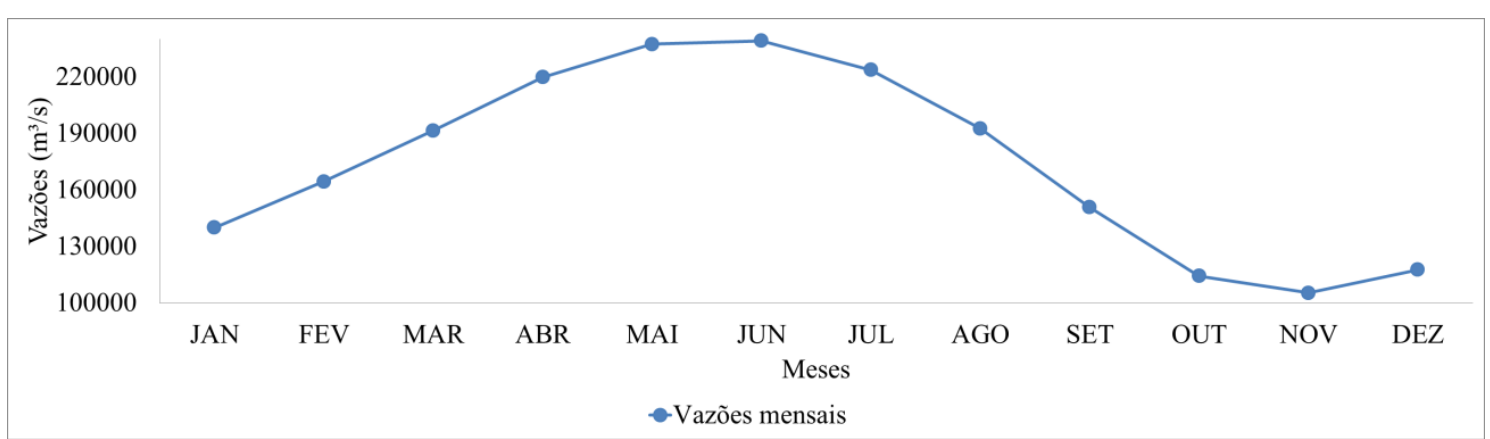

Figura 2 - Regime de vazões médias do rio Amazonas no período de 1970-2013. (Fonte: Do autor).

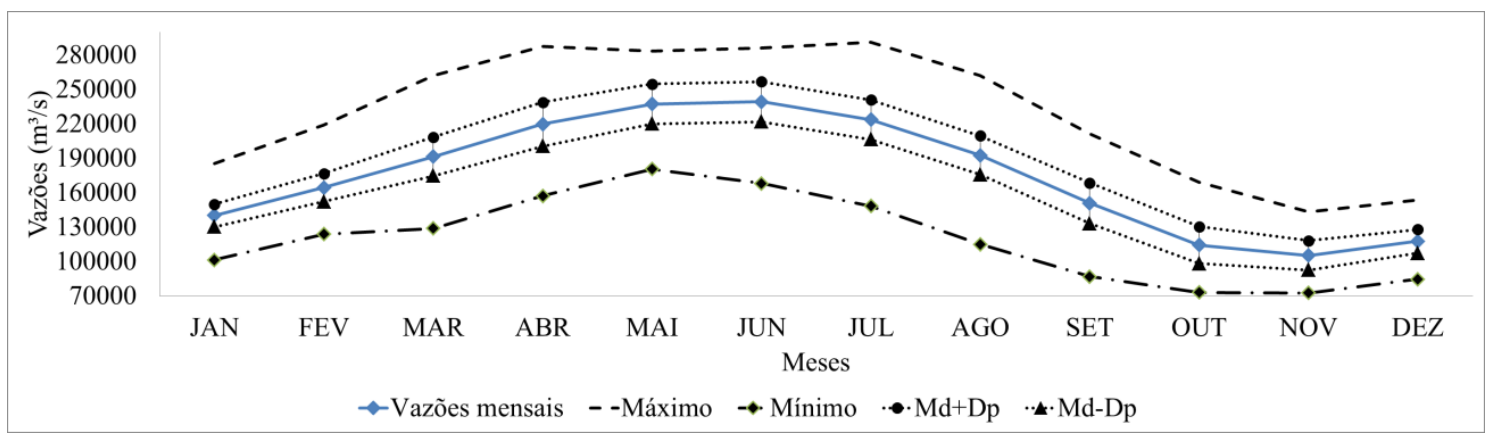

Figura 3 - Regime de vazões médias e as elevações máxima e mínima do rio Amazonas no período de 1970-2013. (Fonte: Do autor).

Já estudos como o de Gallo (2004) mostraram que as vazões mínimas ocorriam em setembro na ordem de $120.000 \mathrm{~m}^{3} / \mathrm{s}$, ou seja, maior que a vazão mínima encontrada neste trabalho e mais antecipada em sua ocorrência.

Ambas as divergências pode ser devido a periodicidade diferente nas análises das séries temporais de dados de vazões médias mensais utilizados. Todavia, o estudo mostra que a série utilizada neste trabalho apresentou comportamento similar às séries observadas em outros trabalhos.
A Figura 2 mostrou que o rio Amazonas apresenta uma vazão média anual de $174.592 \mathrm{~m}^{3} / \mathrm{s}$. Enquanto que a vazão total média dos rios para todo o território brasileiro é estimado em 179.000 $\mathrm{m}^{3} / \mathrm{s}$ conforme a ANA (2007).

O comportamento natural das vazões máximas e mínimas absolutas que compõem a faixa de oscilação hidrológica da bacia do rio Amazonas foi observado na Figura 03 juntamente com as relações entre as vazões médias e o desvio padrão positivo e negativo do regime em cada mês. 
Ao analisar os valores de máximas absolutas mensais percebeu-se dois picos máximos de vazões, um em abril com valor de $287.600 \mathrm{~m}^{3} / \mathrm{s}$ e outro em julho com valor de $291.040 \mathrm{~m}^{3} / \mathrm{s}$, sendo que estas grandes variabilidades de vazão acima da normalidade do rio Amazonas ocorreram no ano de 2009.

Enquanto que ao analisar os valores de mínimo absolutos, o mês de novembro apresentou uma vazão mínima de $72.380 \mathrm{~m}^{3} / \mathrm{s}$ (observado no ano de 1997).

A partir desta expressiva variabilidade hidrológica positiva nos meses de um mesmo período hidrológico, pode-se afirmar que a bacia Amazônica, durante a sazonalidade do ano de 2009, apresentou grande parte do total da vazão na época cheia em relação ao total da vazão na época seca.

Ao analisar a variabilidade da vazão do rio Amazonas no mesmo mês, verifica-se que houve um forte aumento da vazão no mês de abril, onde a variabilidade hidrológica, neste mês, chegou a $67.969 \mathrm{~m}^{3} / \mathrm{s}$ acima da média do regime normal do rio. No mês de julho, a vazão variou $67.487 \mathrm{~m}^{3} / \mathrm{s}$ acima da média do regime normal do rio. Enquanto que no mês de novembro, a vazão variou apenas $32.807 \mathrm{~m}^{3} / \mathrm{s}$ abaixo da média do regime normal do rio.

Os resultados mostram diferentes regimes com grande variabilidade das vazões ao longo do tempo para a bacia Amazônica em função de sua densa e extensa área hidrográfica.

Variação interanual do regime hidrológico.

A Figura 4 apresenta as vazões mínimas anuais do rio Amazonas no período de 1970-2013, juntamente com a vazão média do período total, a $(\bar{x}+\sigma)$ - ponto de início de cheia e a $(\bar{x}-\sigma)$ ponto de início de seca, onde se observou que o tempo influenciou na vazão média encontrada de $98.723 \mathrm{~m}^{3} / \mathrm{s}$ entre os 44 anos da série histórica com variabilidade de intensas proporções.

A região Amazônica é conhecida por sua grande disponibilidade hídrica. No entanto, o trabalho em escala temporal mostrou que houve desvios acentuados na curva no período de vazante do regime hidrológico em 9 (nove) anos da série histórica. Com as maiores flutuações iniciando somente a partir do ano de 1983 e alcançando a ordem de até $72.380 \mathrm{~m}^{3} / \mathrm{s}$ (como ocorrido no ano 1997).

Enquanto, no período de cheia da bacia Amazônica, a vazão alcançou valores superior a vazão média em apenas 7 (sete) anos da série (Figura 04). Com as grandes vazões variando entre os anos neste regime e alcançando até a ordem de $131.620 \mathrm{~m}^{3} / \mathrm{s}$ (como em 1974).

Os anos encontrados de regime de cheia superior a vazão média foram 1973, 1974, 1977, 1978, 1985, 1986 e 1989. Sendo que destes anos o menor valor de vazão registrado na estação foi no ano de 1978 , com o valor de $115.300 \mathrm{~m}^{3} / \mathrm{s}$.

Por outro lado, foram observadas 9 (nove) anos de vazões muito abaixo da média, com a característica de estarem próximos um do outro no final do período chegando a valores de $86.660 \mathrm{~m}^{3} / \mathrm{s}$ (1983), $83.520 \mathrm{~m}^{3} / \mathrm{s}$ (1990), $82.600 \mathrm{~m}^{3} / \mathrm{s}$ (1991), $74.580 \mathrm{~m}^{3} / \mathrm{s}$ (1995), $72.380 \mathrm{~m}^{3} / \mathrm{s}$ (1997), 75.040 $\mathrm{m}^{3} / \mathrm{s} \quad(1998), 72.800 \mathrm{~m}^{3} / \mathrm{s}$ (2005), $77.120 \mathrm{~m}^{3} / \mathrm{s}$ (2010) e $84.160 \mathrm{~m}^{3} / \mathrm{s}$ (2012). Incluindo o ano de 2009, que na Figura 03 apresentou picos de vazões máximas.

Sendo que destes anos a maior vazão registrada na estação foi no ano de 1983 , com o valor de $86.660 \mathrm{~m}^{3} / \mathrm{s}$.

Nos anos de 1991 e 1998 as vazões muito abaixo da média podem ter ocorrido devido nestes mesmos anos ter ocorrido grandes secas que afetaram a Amazônia, detectados nos estudos de Marengo (2006), afetando as vazões da estação de Óbidos, ficando muito abaixo da média.

A baixa vazão encontrada no ano de 2005 coincidiu com a ocorrência de um tipo de anomalia climática que secou o Oeste e o Sul, e não o Centro e o Leste amazônico, como nos anos de El Niño. Segundo Marengo e Silva (2006), em 2005, a seca nos rios da Amazônia causou danos a espécies de mamíferos aquáticos e peixes. Após essa forte seca, desde janeiro de 2006, na região ocorreu uma forte enchente (Marengo e Silva, 2006).

A Figura 4 mostra também uma sequência de anos de vazão baixa no período de 1980-1990. E um crescimento dos valores de vazão em Óbidos a partir de 2002. Esse aumento dos valores de vazão indica que a regulação do fluxo teve influência maior na elevação das vazões mínimas de que sobre a diminuição das vazões máximas.

No final do período analisado, a partir de 1989, houve um aumento sazonal em relação à amplitude média da vazão de $87.727 \mathrm{~m}^{3} / \mathrm{s}$.

A Figura 5 mostra que em 1992 a amplitude sazonal da vazão do rio Amazonas obteve grande diminuição, chegando a $54.903 \mathrm{~m}^{3} / \mathrm{s}$. Além disso, mostra que a amplitude sazonal variou de $54.903 \mathrm{~m}^{3} / \mathrm{s}$ (em 1992) a $122.000 \mathrm{~m}^{3} / \mathrm{s}(\mathrm{em}$ 2009), devido a fortes níveis mínimos registrados (Figura 05), corroborando com os estudos de Marengo (2006) que não detectou tendências significativas para aumento vazões desde meados do século XX na Amazônia.

Em Óbidos, a amplitude obteve maior variabilidade a partir do desvio $\left(16.572 \mathrm{~m}^{3} / \mathrm{s}\right)$ nos 
anos de 1997, 1999, 2006, 2009 e 2012. Enquanto que as menores variabilidades da amplitude ocorreram em 1973, 1977, 1980, 1983, 1985, 1986, 1992 e 2004.

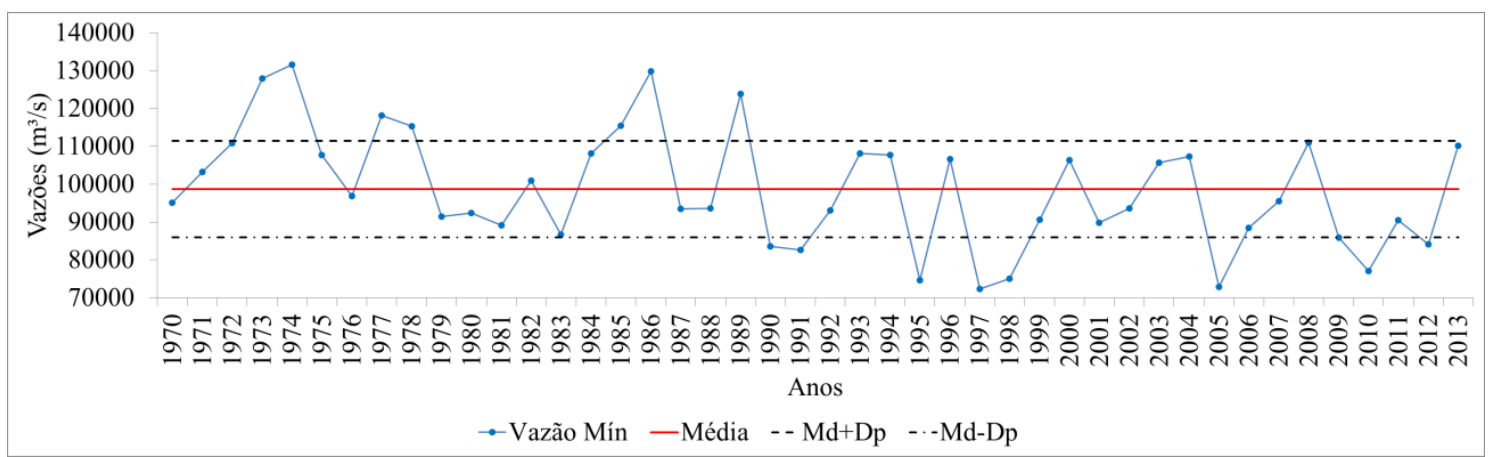

Figura 4 - Regime das vazões anuais do rio Amazonas no período de 1970-2013. (Fonte: Do autor).

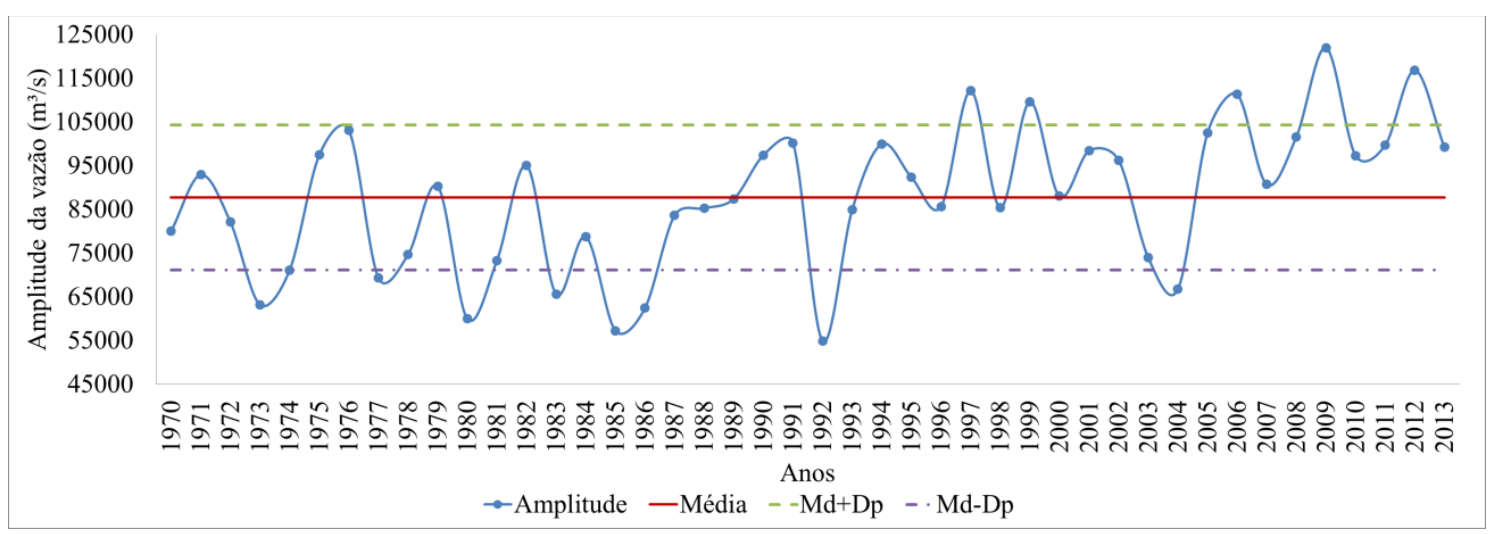

Figura 5 - Amplitude das vazões anuais do rio Amazonas no período de 1970-2013. (Fonte: Do autor).

Variação do regime hidrológico diante aos eventos extremos

Após a análise da variabilidade do regime hidrológico da bacia Amazônica brasileira, pôde-se verificar que o tempo contribuiu na persistência das baixas vazões em escala de bacia. Onde foi registrado vazão alcançando valor de até 72.380 $\mathrm{m}^{3} / \mathrm{s}$.

O estudo da variabilidade do regime hidrológico diante aos eventos extremos ocorreu a partir da Tabela 01 que ilustra a intensidade do El Niño e La Niña, disponibilizada pelo CPTEC, mostrando os anos em que estes fenômenos modularam a intensificação de eventos climáticos extremos sobre a bacia Amazônica, no período de 1970 a 2013 e consequentemente o comportamento das vazões nos regimes de vazante e de cheia.

Após a análise individual de cada um dos anos, pôde-se verificar a ocorrência, nestes anos, de anomalias de TSM negativas e positivas diferenciadas na bacia Amazônica.

A Figura 6 apresenta a vazão normalizada na bacia do rio Amazonas, mostrando que os maiores eventos extremos positivos ocorreram na década de 80, coincidindo com anos de La Niña de
1985, 1988 e 1989, já os maiores eventos negativos foram presentes na década de 90 e no ano de 2010.

Os anos de 1990, 1991, 1992, 1995, 1997, 1998, 2005 e 2010 foram anos com acentuados desvios extremos negativos da vazão no regime hidrológico, conforme Figura 6. O ano de 1995 apresentou evento negativo extremo e o de 2010, evento negativo muito extremo, ou seja, uma seca severa, concordando com os estudos de Marengo et al. (2008) e Espinoza et al. (2011).

Enquanto que a Figura 06 mostra os anos de 1973, 1974, 1985 e 1989 com acentuados desvios extremos positivos da vazão no regime hidrológico. Conforme a Tabela 1 disponibilizada no portal do CPTEC em 1973, 1974, 1985 e 1989 foram anos de ocorrência de La Niña. Assim, para este caso, pode-se afirmar que esta expressiva variabilidade hidrológica positiva pode ser caracterizada como efeito do fenômeno.

Ressalta-se que embora não tenha influenciado na vazão normalizada apresentada na Figura 6, o ano de 2009, para a bacia Amazônica, foi ano de cheia atípica do ponto de vista hidroclimatológico. Eventos atípicos como o de 2009 não são comuns, mas já ocorreram na região Amazônica. Estudos sobre tais eventos são mais comuns em condições de forte seca. 
Eventos como a seca de 2005 apresentaram também suas peculiaridades do ponto de vista climatológico. A seca de 2005 caracterizou-se por apresentar uma baixa vazão, ocorrida não devido ausência de El Niño, mas pelo fato das águas do oceano Atlântico Norte estarem anomalamente quentes (Marengo et al., 2008; Zeng et al., 2008).

$\mathrm{O}$ que se percebe é que eventos extremos ocorridos nos regimes de cheias e vazantes, sobre a região Amazônica, podem influenciar de maneira diferente ao longo do tempo e do espaço, como nas diferenças de pico das vazões no tempo das cheias, na década de 80 , e no extremo das vazantes, nos eventos negativos ao longo dos anos 90, anos de 2000 e 2010.

A partir da Figura 6 percebe-se que houve a ocorrência de El Niño nos anos de 1991 e 1992, coincidindo com uma anomalia de vazão negativa $\left(16.124 \mathrm{~m}^{3} / \mathrm{s}\right)$ para o ano de 1991 abaixo da média, que persistiu no ano seguinte, pois a vazão em 1992 continuou abaixo da média $\left(5.604 \mathrm{~m}^{3} / \mathrm{s}\right)$. Dessa forma, para este caso, pode-se afirmar que a variabilidade do regime nestes anos foi afetada pelo fenômeno, concordando com Zeng (1999) que estudou a influencia do fenômeno El NiñoOscilação Sul (ENOS) sobre o escoamento na bacia Amazônica, e concluiu que a mesma pode ocorrer até sete meses após o inicio do evento, afetando o regime hidrológico do ano em curso e também do ano seguinte.

A Tabela 1 registrou a ocorrência de $17 \mathrm{El}$ Niños no período de 1970 a 2013. Especificamente nos anos de 1970, 1976, 1977, 1979, 1980, 1983, 1987, 1991-1992, 1995, 1997-1998, 2002, 20062007, 2009 e 2010. E a Figura 06 mostra que anomalias negativas persistiram ao longo dos anos 90 e 2000.

No ano de 1970 houve uma forte diminuição de vazão na Amazônia, coincidindo com a ocorrência do fenômeno El Niño moderado, e que, portanto, pode ter causado uma anomalia de vazão negativa $\left(3.624 \mathrm{~m}^{3} / \mathrm{s}\right)$ neste ano.

As vazões do rio Amazonas na estação de Óbidos mostram valores maiores que a média durante os episódios de La Niña ocorridos em 1975-76 e 1988-89, comparados com valores mais baixos nos anos de El Niño, ocorridos em 1982-83 e 1986-87. Durante o ano de 1998, após a rápida desintensificação do fenômeno El Niño em maio e junho, observou-se um súbito resfriamento das águas do Pacífico Equatorial Central (CPTEC, 2001).

O estudo de Guedes (2013) confirma que em 1989 ocorreu uma das maiores cheias dos últimos cem anos, e uma vazante ocorrida em 1998. No caso da cheia foi precedida por evento forte de La Niña em 1989. Nestes períodos o estoque de água continental é também elevado e segue uma tendência de aumento em escala longa de tempo (Zeng et al., 2008).

Ainda conforme a Figura 6 pode-se verificar que os anos de 1986 e 1977 foram de vazões extremas positivas. Guedes (2013) ainda afirma que nestes anos, a ocorrência do fenômeno de El Niño, não foi determinante para a ocorrência de anomalias negativas, pois neste período o estoque de água continental na Amazônia pôde manter-se elevado.

Dessa forma, comprova-se que a componente vazão do rio Amazonas foi afetada por anomalias na década de 80 . Onde os anos de altas vazões coincidiram com ano de La Niña e seus efeitos.

Apesar disso, pode-se afirmar que os eventos La Niña de intensidade forte influenciam parcialmente na vazão da calha do rio Amazonas, podendo assim causar extremos de cheia. Esse estudo também pode ser comprovado por Espinoza et al. (2014) que analisaram a relação da elevada vazão e eventos de La Niña para o rio Beni durante os eventos com intensidade forte e moderada.

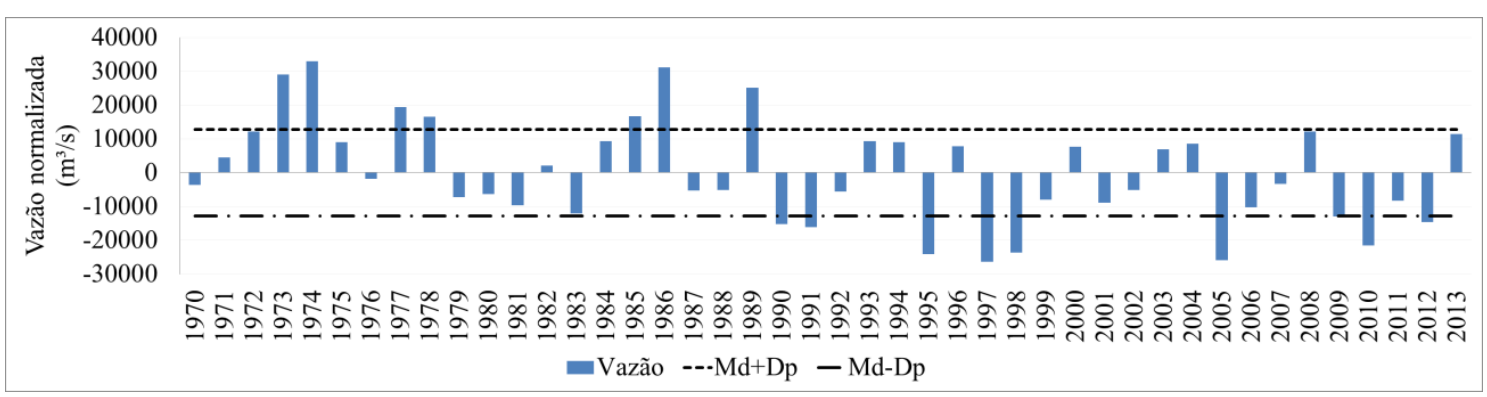

Figura 6-Fenômenos de EN (seta em vermelho) e LN (seta em amarelo) em vazão no regime hidrológico do rio Amazonas no período de 1970-2013. (Fonte: Do autor).

Disponibilidade hídrica do rio amazonas em função da Q95\%
A partir da característica do regime hidrológico na bacia Amazônica, ao longo 
dos 44 anos analisados, de apresentar mais anos de vazão abaixo da média se comparado aos outros anos, a pesquisa investigou se os valores de vazão observada nestes anos alcançaram os níveis mínimos recomendados pela Agência Nacional de Águas (ANA), o quantil de vazão Q95\%, em boa parte para procedimentos administrativos de licenciamento ambiental e concessão de outorga do uso da água no País e, neste trabalho, para a manutenção dos ecossistemas da bacia Amazônica em situações de eventos extremos no período de 1970 a 2013.

Assim, a vazão Q95\% foi determinada separadamente tanto para os 44 anos quanto para os 12 meses ao longo dos anos da série histórica analisada.

Análise da disponibilidade hídrica anual diante a vazão Q95\%

A partir do período entre os anos de 1970 a 2013, determinaram-se as novas vazões Q95\% para cada mês com os dados dos anos da série como referência a ser mantida na bacia Amazônica ao longo dos 12 meses do ano para assegurar água no leito do rio e às diversas espécies do ecossistema amazônico, conforme Tabela 3.

\begin{tabular}{|c|c|c|c|c|c|c|}
\hline Mês & Jan & Fev & Mar & Abr & Mai & Jun \\
\hline & 106.000 & 130.540 & 147.180 & 178.327 & 192.138 & 190.827 \\
\cline { 2 - 7 } $\begin{array}{l}\text { Q95\% } \\
\left(\mathrm{m}^{3} / \mathrm{s}\right)\end{array}$ & Jul & Ago & Set & Out & Nov & Dez \\
\cline { 2 - 7 } & 178.322 & 151.233 & 113.886 & 80.545 & 83.339 & 97.164 \\
\hline
\end{tabular}

Tabela 3 - Vazões Q95\% para ser mantida no rio Amazonas em cada mês no período de cheia e no período de vazante. (Fonte: Do autor).

Nota-se que, como foi observado na Figura 02, os meses de abril a julho foram de cheia do rio Amazonas em Óbidos. Porém, a partir da vazão de referência, as vazões mensais se tornam mais restritivas para o rio Amazonas.

A Tabela 3 ainda mostra que no mês de outubro o rio Amazonas em Óbidos se torna mais restritivo com um quantil de vazão disponível (Q95\%) de $80.545 \mathrm{~m}^{3} / \mathrm{s}$, aproximadamente. Enquanto que no mês de maio, o rio Amazonas alcança a vazão menos restritiva de $192.138 \mathrm{~m}^{3} / \mathrm{s}$.

Análise da disponibilidade hídrica interanual diante a vazão Q95\%

A análise da variabilidade interanual, já citado anteriormente, mostrou que os anos de 1983, 1990, 1991,1995, 1997, 1998, 2005, 2009, 2010 e 2012 foram os de vazão muito abaixo da média no regime hidrológico determinado neste trabalho para a bacia Amazônica.

Dessa forma, foi investigado se os valores mínimos de vazão observada nestes anos coincidiram com os níveis mínimos recomendados pela vazão Q95\% interanual.

Assim, o trabalho comparou as vazões anteriormente observadas em seu regime natural e sazonal, característico da região amazônica, com a vazão Q95\% de cada mês da Tabela 03. Dessa forma, analisou-se a periodicidade de quantidade de água para a manutenção do ecossistema amazônico ao longo dos 44 anos tanto para as séries históricas de vazões entre anos (análise interanual) quanto para as séries históricas de vazões mensais (análise anual).

Ao fixar a vazão Q95\% para os anos do período de 1970-2013, encontrou-se um valor de referência de $89.630 \mathrm{~m}^{3} / \mathrm{s}$, como verificado no histograma de vazões da Figura 7.

A partir desta referência, a Figura 07 mostrou que houve flutuações significativas entorno da vazão Q95\% anual, onde todos os anos que apresentaram vazões mínimas ficaram abaixo até mesmo da vazão recomendada por lei, como ocorrido nos anos 1983, 1990, 1991, 1995, 1997, 1998, 2005, 2006, 2009, 2010 e 2012.

Enquanto que ao fixar a vazão Q95\% para cada ano do período de 1970-2013, de maneira 
separada, para efetuarmos os cálculos da equação da disponibilidade hídrica $\left(\mathrm{DH}_{\mathrm{ti}}\right)$, sugerida neste trabalho, para cada ano da série, a Figura 07 mostrou que na maior parte dos anos não ocorreu problema de oferta hídrica. Nestes casos, os valores das vazões mínimas observadas no rio Amazonas ao longo dos anos foram superadas pelas vazões Q95\%. Sendo que a disponibilidade hídrica nos anos 1973, 1974, 1985 e 1989 foram as maiores, e acompanharam os máximos das vazões mínimas observadas nestes anos que estavam sobre influência de La Niña.

Além disso, no ano de 1977, houve ocorrência de El Niño, entretanto a vazão mínima observada, assim como a disponibilidade hídrica, foi elevada, indicando que o evento de El Niño não influenciou, de modo a reduzir as vazões da bacia do rio Amazonas. Este fato também foi observado por Guedes (2013), que concluiu, que neste mesmo ano, o estoque de água continental na Amazônia manteve-se elevado.

Por outro lado, a Figura 7 mostra ainda que alguns dos anos que flutuaram minimamente entorno da vazão de referência Q95\% anual de $89.630 \mathrm{~m}^{3} / \mathrm{s}$ também foram os que apresentaram os índices de vazão disponível baixo com valores iguais ou inferiores a vazão referência para o trabalho (Q95\%) de cada mês, especificamente 1970, 1971, 1980, 1983, 1992, 1995, 1997, 1998, 2005, 2010 e 2012.

Ao longo do período de 1970-2013, em 12 anos a disponibilidade hídrica foi a mais crítica por apresentar valores negativos, o que significa que a vazão do rio amazonas nestes anos, não favoreceram as necessidades de manutenção dos ecossistemas, provavelmente causando estresses hídricos. Sendo que os anos de 1995, 1997, 1998 e 2005 foram de disponibilidades hídricas muito negativas, coincidindo com as mínimas vazões observadas nos anos que estavam sobre influência de El Niño. Nos anos de 1997 e 2005 foram observados os máximos de disponibilidade hídrica negativa dos 44 anos analisados, atingindo valores de $-17.250 \mathrm{~m}^{3} / \mathrm{s}$ e $-16.830 \mathrm{~m}^{3} / \mathrm{s}$ respectivamente. Ressalta-se que o ano de 1997 foi de El Niño muito forte, porém, o ano de 2005 foi ano de seca devido as águas do oceano Atlântico Norte anomalamente quentes (Marengo et al., 2008; Zeng et al., 2008).

Além disso, a Figura 7 mostra que o ano de 1983 também apresentou índices de disponibilidade hídrica negativa junto aos ano de 1992, ano com grande indicativo de estresse hídrico.

Portanto a partir dos anos 80 , verificou-se que os anos tornaram-se altamente restritivos, chegando a níveis não sustentáveis por apresentaram altos índices de disponibilidade hídrica negativa. Ressalta-se que nesse período houve ocorrência do El Niño de fraca intensidade (1983-1984) apresentado no portal do CPTEC. Nesse caso, pode-se afirmar que a vazão disponível nos anos 1983 e 1992 não foi suficiente para suprir a vazão Q95\% exigida.

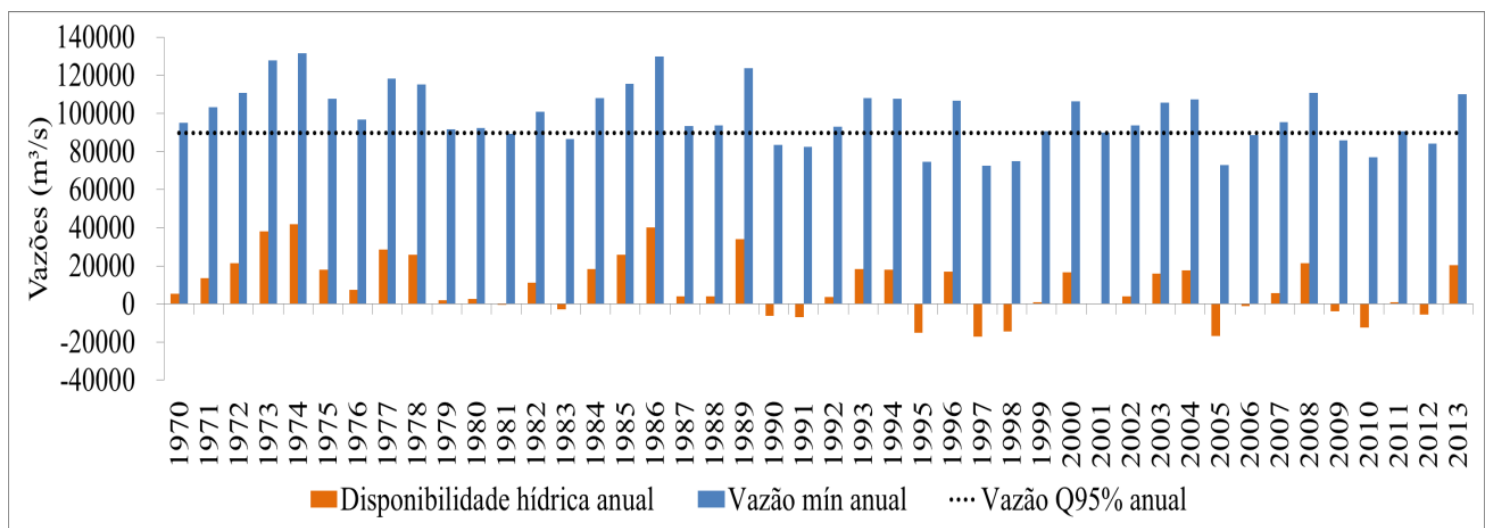

Figura 7 - Comparação entre vazões mínimas observadas e as disponibilidades hídricas anuais do rio Amazonas. (Fonte: Do autor).

O trabalho até aqui definiu como período de vazante somente o compreendido entre os meses de setembro a dezembro. Ocorre que desde a década de 80, as vazões sazonais do rio Amazonas têm mostrado forte aumento na amplitude da vazão mínima anual, ou seja, com maiores diferenças de vazão entre as épocas de cheia e vazante, como mostrado. No entanto, acompanhado também dos piores indicativos de estresse hídrico, pois estes picos de vazão vêm ocorrendo em meses muito próximos uns dos outros, no período de vazante.

Assim, os meses que antecedem o período de vazante, como os meses de julho e agosto, também devem ser levados em consideração.

$\mathrm{Na}$ estação fluviométrica de Óbidos, os anos de 2005 e no ano da seca de 2010 alcançaram 
valores significantes de variabilidade (Figura 04). Esses períodos de déficit de água, concordam com os estudos de Frappart et al. (2012) que encontraram uma queda, porém de precipitação, utilizando dados do Gravity Recovery and Climate Experiment (GRACE) para a seca de 2005.

No ano de 1997, a vazão disponível se mostrou muito restritivo chegando a nível não sustentável,mostrado no trabalho, coincidindo com a ocorrência do ano de El Niño.

Houve anos de El Niño que não apresentaram índices de disponibilidade hídrica críticos. Como ocorreu nos anos de 1979, 1987, 1991, 2002, 2006-2007 e 2009 que apresentaram mínimas vazões de $91.500 \mathrm{~m}^{3} / \mathrm{s}, 93.480 \mathrm{~m}^{3} / \mathrm{s}$, $82.600 \mathrm{~m}^{3} / \mathrm{s}, 93.660 \mathrm{~m}^{3} / \mathrm{s}, 88.440 \mathrm{~m}^{3} / \mathrm{s}, 95.460 \mathrm{~m}^{3} / \mathrm{s}$ e $85.820 \mathrm{~m}^{3} / \mathrm{s}$ respectivamente. Porém em índices acima da vazão limite para o trabalho (Q95\%) de cada mês do ano para assegurar a sustentabilidade deste ecossistema amazônico. Dessa forma, embora tenham ocorrido os anos mais intensos de El Niño, ao longo da série, nem todos refletiu na vazão do rio Amazonas (Marengo et al., 2008; Espinoza et al., 2011; Frappart et al., 2012; Marengo et al., 2012).

Além disso, houve anos de disponibilidade hídrica crítica que não coincidiram com anos de El Niño. Como ocorreu nos anos de 1970, 1971, 1995, 2005 e 2012.

Dessa forma, a Figura 7 mostra que a disponibilidade hídrica se mostra restritiva (valores negativos muito elevados) a apenas alguns anos.

Conforme apresentado na Figura 7, o rio Amazonas nos meses de janeiro e março possui uma capacidade de disponibilidade hídrica bem superior à vazão de referência utilizada na legislação.

Entretanto, observa-se também que o comportamento da descarga mínima na bacia do rio Amazonas ao longo do tempo foi desfavorável em alguns períodos com valores de disponibilidade hídrica muito negativo, provavelmente causando estresses hídricos.

Ao analisar os períodos de eventos de cheia e vazante que influenciam no rio Amazonas, observou-se uma relação com alguns anos mostrados de ocorrência de eventos extremos ao longo da série histórica.

Embora uma alta disponibilidade hídrica que associado a baixa densidade demográfica e a um desenvolvimento econômico ainda incipiente faz com que a região amazônica não apresente problemas de disponibilidade hídrica em grande escala.

\section{Conclusões}

Os resultados mostram o regime hidrológico do rio Amazonas e a regulação das cheias e vazantes através da faixa de oscilação hidrológica natural da bacia amazônica.

A análise mensal mostrou que os meses de abril a julho foram épocas de cheia e a época de vazante ocorreu de setembro a dezembro, compondo a sazonalidade do ciclo hidrológico do rio Amazonas. Sendo o mês de outubro como o mais restritivo. Enquanto o mês de maio, o rio Amazonas apresentou a vazão menos restritiva.

Neste trabalho pôde-se concluir que a variabilidade temporal contribuiu na persistência das baixas vazões da bacia Amazônica Brasileira, onde foi registrada vazão alcançando valor de até $72.380 \mathrm{~m}^{3} / \mathrm{s}$.

Ao longo do período estudado, a bacia mostrou que embora a região Amazônica seja conhecida por sua grande disponibilidade hídrica, anos com baixas vazões têm sido registrados. E com a característica de persistência em relação aos anos de altas vazões na bacia hidrográfica Amazônica. Com as maiores flutuações iniciando somente a partir do ano de 1983 e alcançando até a ordem de $131.620 \mathrm{~m}^{3} / \mathrm{s}$ (como em 1974).

Pôde-se concluir que significativos aumentos de vazões não foram detectados desde meados do século XX na Amazônia, pois o aumento sazonal a partir de 1989 em relação à amplitude média da vazão de $87.727 \mathrm{~m}^{3} / \mathrm{s}$, que variou de $54.903 \mathrm{~m}^{3} / \mathrm{s}\left(\mathrm{em} \mathrm{1992)} \mathrm{a} 122.000 \mathrm{~m}^{3} / \mathrm{s}\right.$ (em 2009), foi devido a fortes níveis mínimos registrados no período analisado.

Além da influência temporal, o estudo mostrou que o comportamento das vazões na bacia Amazônica sofreu a influência de anomalias de TSM negativas e positivas moduladas pela intensidade do El Niño e La Niña em cada ano da série.

No entanto, as variabilidades hidrológicas na Amazônia não são causadas somente pelos fenômenos de El Niño ou La Niña, ou seja, elevados índices fluviométricos podem ou não serem afetados pela La Niña e baixos índices pelo El Niño. Assim, o ano de 2009, para a bacia Amazônica, foi ano de cheia atípica do ponto de vista hidro-climatológico que não influenciou na vazão normalizada apresentada neste trabalho. Enquanto que o ano de 2005 foi ano de seca caracterizado por apresentar uma baixa vazão, que ocorreu não devido ausência de El Niño, mas pelo fato das águas do oceano Atlântico Norte estarem anomalamente quentes.

Quando se analisou cada ano da série histórica pôde-se comprovar que o fenômeno El Niño-Oscilação Sul (ENOS) efeta o regime hidrológico do ano em curso e também do ano 
seguinte do escoamento na bacia Amazônica, pois observou-se ocorrência de El Niño nos anos de 1991 e 1992, coincidindo com uma anomalia de vazão negativa $\left(16.124 \mathrm{~m}^{3} / \mathrm{s}\right)$ para o ano de 1991 abaixo da média, que persistiu no ano seguinte, pois a vazão em 1992 continuou abaixo da média (5.604 $\left.\mathrm{m}^{3} / \mathrm{s}\right)$.

A análise interanual mostrou que a vazão na bacia do rio Amazonas ao longo do tempo foi desfavorável em anos de extremos negativos e o método dos Percentis (especificamente a ordem quantílica Q95\%) permitiu quantificar a disponibilidade hídrica, ao longo dos meses e dos anos da série temporal, em que os valores mínimos de vazão observada do rio Amazonas não foi

\section{Referências}

Adamowski, J.; Fung Chan, H.; Prasher, S. O.; Ozga-Zielinski, B.; Sliusarieva, A., 2012. Comparison of multiple linear and nonlinear regression, autoregressive integrated moving average, artificial neural network, and wavelet artificial neural network methods for urban water demand forecasting in Montreal, Canada. Water Resource Research, 48, n. 1, W01528. Disponível: doi:10.1029/2010WR009945. Acesso: 17 jun. 2017.

ANA. Agência Nacional de Águas,2007. Disponibilidade e demanda de recursos hídricos no Brasil. Cadernos de Recursos Hídricos. 2. Brasília..

Almeida, A. C. L. de., 2014. Chuva, lamaçal e inundação no Rio de Janeiro do século XIX: entre a providência divina e o poder público. Revista do Arquivo Geral da Cidade do Rio de Janeiro, 8, 117-134.

Arnold, J. G.; Moriasi, D. N.; Gassman, P. W.; Abbaspour, K. C.; White, M. J.; Srinivasan, R. et al., 2012. SWAT: Model use calibration and validation. Transactions of ASABE, 55, 14941508.

BRASIL. Agência Nacional de Transportes Aquaviários. Bacia Amazônica. Plano Nacional de Integração Hidroviária. Brasília: ANTAQ, 2013 (Relatório Executivo). Disponível: http://www.antaq.gov.br/portal/PNIH/BaciaA mazonica.pdf. Acesso em 19 dez. 2016.

Callède, J.,1996. As descargas do rio Amazonas em Óbidos. Horizon pleins textes, la base de ressources documentaires de l'IRD. Disponível: http://www.documentation.ird.fr/hor/fdi:01 0024777. Acesso 17 jan. 2019.

Callède, J.;Guyot, J.L.; Ronchail, J.; Molinier, M. e Oliveira, E., 2002. L'Amazone à Óbidos suficiente para a manutenção dos ecossistemas da bacia Amazônica através da apresentação de índices de disponibilidade hídrica muito negativa, abaixo da exigida pela legislação para garantir a sustentabilidade das diversas espécies do ecossistema.

Ressalta-se que a distribuição temporal das vazões mínimas é importante para projetos como abastecimento de água, irrigação e energia elétrica. As vazões mínimas que ocorrem em época de estiagem são utilizadas nestes estudos dentro de uma das seguintes finalidades: análise, projeto, estimativa, regulamentação legal, operação e planejamento.

(Brésil): Étude statistique dês débits et bilan hydrologique. Hydrological Sciences Journal, 47, 321-333.Disponível: DOI: 10.1080/02626660209492933. Acesso 12out. 2018.

Callède, J., J. L. Guyot, J. Ronchail, Y. L' Hôte, H. Niel, and E. de Oliveira, 2004. Evolution du débit de I'Amazone à Obidos de 1903 à 1999/ Evolution of the River Amazon's discharge at Óbidos from 1903 to 1999, Hydrological Sciences Journal, 49:1, 85-97. Disponível: doi: 10.1623/hysj.49.1.85.53992. Acesso 16 set. 2018.

Centro de Previsão de Tempo e Estudos Climáticos (CPTEC). Tabela de anos de El Niño / La Niña. Disponível:http://www.cptec.inpe.br/products/l aninha/ lanitabp. Acesso: 09 abr. 2001.

Coutinho, E. C., 2016. O regime hidrológico da bacia amazônica e análise das relações de eventos hidrológicos extremos e seus impactos na sociedade.. Tese (Doutorado). Belém.; Instituto de Geociências, Universidade Federal do Pará.

Centro de Previsão de Tempo e Estudos Climáticos - CPTEC. Instituto Nacional de Pesquisas Espaciais - INPE, 2001. Tabela de anos de El Niño/La Niña. Disponível:http://www.cptec.inpe.br/products/l aninha/ lanitabp. Acesso: 09 abr. 2001.

Cruz, J. C.; Tucci, C. E. M., 2008. Estimativa da disponibilidade hídrica através da curva de permanência. RBRH: Revista Brasileira de Recursos Hídricos, 13, 111-124.

Detzel, D. H. M.; Mine, M. R. M.; Bessa, M. R.; Bloot, M., 2014. Cenários sintéticos de vazões para grandes sistemas hídricos através de modelos contemporâneos e amostragem. RBRH: Revista Brasileira de Recursos Hídricos, 19, 17-28.

Detzel, D. H. M.; Mine, M. R. M.,2011. Generation of daily synthetic precipitation series: analyses 
and application in La Plata river Basin. Journal of Hydrology., 5, 69-77.

EM-DAT: The International Disaster DATABASE/ Centre forResearch on The Epidemiology of Disasters - CRED, 2015. Disaster profile. Lovaina, Bélgica.

Espinoza, J.C., Ronchail, J.;Guyot, J.L.; Junquas, C.; Vauchel, P.; Lavado, W.;Drapeau, G. E Pombosa R., 2011.Climate variability and extreme drought in the upper Solimões River (Western Amazon Basin): Understanding the exceptional 2010 drought. Geophysical Research Letters, 38, L13406. Disponível: doi:10.1029/2011GL047862. Acesso: 10mar. 2018.

Frappart, F.; Papa, F.; Silva, J.S.; Ramillien, G.; Prigent, C.; Seyler, F.; Calmant, S., 2012.Surface freshwater storage and dynamics in the Amazon basin during the 2005 exceptional drought.. Environmental Research Letters. 7.044010 (7p). Disponível: DOI:10.1088/17489326/7/4/ 044010.Acesso: 09 abr. 2018.

Gallo, M. N.,2004. A Influência da vazão fluvial sobre a propagação da maré no estuário do Rio Amazonas. Dissertação (Mestrado). Rio de Janeiro. Instituto Alberto Luiz Coimbra de PósGraduação e Pesquisa de Engenharia, da Universidade Federal do Rio de Janeiro.

Guedes, A. E. D. S.; Candido, L. A.; Santos, A. R. S. do E.,2013. Variabilidade do estoque de água continental e sua relação com as cheias e vazantes extremas na Amazônia. Revista Ambiente e Água.88-99.

Loewen, A. R.; Pinheiro, A., 2017. Overland flow generation mechanisms in the Concórdia River basin, in southern Brazil. Revista Brasileira de Recursos Hídricos, $22 . \quad$ Disponível: http://dx.doi.org/10.1590/2318-

0331.011716026. Access: 30 jan. 2017.

Lucas, E. W. M.. SOUSA, F. A. S., SILVA, F. D. S., LÚCIO, P. S. ,2009. Modelagem hidrológica determinística e estocástica aplicada à região hidrográfica do Xingu - Pará. Revista Brasileira de Meteorologia, 24, 308-322.

Marengo, J. A., 2006. Mudanças climáticas globais e seus efeitos sobre a biodiversidade: caracterização do clima atual e definição das alterações climáticas para o território brasileiro ao longo do século XXI. $2^{\circ}$ ed, Ministério do Meio Ambiente.

Marengo, J., Silva Dias, P., 2006. Águas Doces do Brasil: Capital Ecológico, Uso e Conservação, in: A. Rebouças, B., Braga e J. Tundisi. Mudanças climáticas globais e seus impactos nos recursos hídricos. Editora Escrituras, São Paulo, pp. 63-109.
Marengo, J. A., 2004. Interdecadal variability and trends of rainfall across the Amazon basin. Theoretical and Applied Climatology, 78, 7996.

Marengo, J. A.; Tomasella, J.; Soares, W. R.; Alves, L. M. E Nobre, C. A., 2012. Extreme climatic events in the Amazon basin. Theoretical and Applied Climatology, 107, 7385.

Marengo, J. A.; Nobre, C. A.; Tomasella, J.; Oyama, M. D.; Oliveira, G. V. S.; Oliveira, R.; Camargo, H.; Alves, L. M.; Brown., F., 2008. The drough to Amazonia in 2005. Journal of Climate, 21,495-516.

Mendes, C. A. B.; Cirilo, J. A., 2013. Geoprocessamento em recursos hídricos: princípios, integração e aplicação. 2. ed. Porto Alegre.

Niu, J.; Sivakumar, B., 2013.Scale-dependent synthetic streamflow generation using a continuous wavelet transform. Journal of Hydrology.,. 496,. 71-78.

Oliveira, V. P.; Mafra, M. V. P.; Soares, A. P. A.,2012. Eventos climáticos extremos na Amazônia e suas implicações no município de Manaquiri (AM). Revista Geonorte, 1, 977 987.

Prosdocimi, I.; Kjeldsen, T. R.; Svensson, C., 2014.Non-stationarity in annual and seasonal series of peak flow and precipitation in the UK.. Natural Hazards and Earth System Sciences, 14. Disponível: http://dx.doi.org/10.5194/nhess-141125. Acesso 08 jul. 2018.

Rasmussen, P. F., 2013. Multisite precipitation generation using a latent autoregressive mode. Water Resources Research, 49, 1845-1857.

Santos, J. Y. G.; Carvalho Neto, J. G.; Silva, R. M.; Montenegro, S. M. G. L.; Santos, C. A. G. 2013. Aplicação do modelo SWAT para a simulação chuva-vazão na Bacia do Rio Tapacurá, Estado de Pernambuco. Anais Simpósio Brasileiro de Recursos Hídricos. Bento Gonçalves. RS, Brasil, pp.01-08.

Silva, A. T.; Portela, M. M., 2013. Stochastic assessment of reservoir storage-yield relationships in Portugal. Journal of Hydrologic Engineering, 18, 567-575.

Viana, J. F. de S.; Montenegro, S. M. G. L.; Silva, B. B. da; Silva, R. M. da; Sousa, W. dos S., 2018. Modelagem Hidrológica da Bacia Hidrográfica do Rio Pirapama - PE utilizando o modelo SWAT. Journal of Environmental Analysis and Progress. 3, 155-172.

Zeng, N, Yoon, J. H., Mariotti, A., Swenson, S., 2008. Variability of Basin-Scale Terrestrial Water Storage from a PER Water Budget 
Method: The Amazon and the Mississippi. Journal of Climate, 21, 248-265.

Zeng, N., 1999. Seasonal cycle and interannual variability in the Amazon hydrologic cycle. Journal of Geophysical Research. 104, 90979106.
Zeng, N.; Yoon, J-H.; Marengo, J. A.; Subramaniam, A.; Nobre, C. A.; Mariotti, A. e Neelin, J. D., 2008. Causes and impacts of the 2005 Amazon drought. Environmental Research Letters. 3, Disponível: doi: 10.1088/1748-9326/3/1/014002. Acesso: 15 jun. 2018. 